\title{
POR UM LUGAR NO IMPÉRIO: INGLESIDADE, PERTENCIMENTO NEGRO E MEMÓRIA NACIONAL EM DOIS CONTOS DE ANDREA LEVY
}

\author{
Denise Almeida Silva* \\ Universidade Regional Integrada do Alto Uruguai e das Missões \\ Frederico Westphalen, Rio Grande do Sul, BR
}

\section{Resumo}

Este trabalho objetiva examinar a interrogação da inglesidade (Englishness) pela ficcionista britânica negra Andrea Levy a partir do lugar ocupado por ela como cidadã britânica, descendente de imigrantes caribenhos negros. O questionamento é situado no quadro da construção identitária que segue ao contato dos ingleses com seus outros, especialmente no contexto da geração Windrush. Entrevistas e, sobretudo, o ensaio "Back to my own country" ajudam a dimensionar a influência da prática e pensamento racista tanto nas relações sociais e culturais quanto na invisibilização da escravidão negra na história oficial da Inglaterra. Considera-se a escrita como a forma escolhida por Levy para posicionar-se frente a essa omissão histórica, e analisam-se, como forma de exemplificar tal práxis ficcional, dois contos que visibilizam as relações entre os coloniais negros e a população hegemônica inglesa, "That polite way that English people have" e "The empty pram".

Palavras-chave: Andrea Levy; Identidade; Inglesidade; Imigração negra; Pertencimento

\section{IN SEARCH OF A PLACE IN THE EMPIRE: ENGLISHNESS, BLACK BELONGING AND NATIONAL MEMORY IN TWO SHORT STORIES BY ANDREA LEVY}

\begin{abstract}
This essay aims at investigating the interrogation of Englishness carried out by the black English writer Andrea Levy from within the place she occupies as an English citizen who descends from black Caribbean immigrants. This interrogation takes place in the context of the identity construction that follows the encounter between the English and their others, especially in the Windrush generation. Interviews and the essay "Back to my own country" (2014) provide insights for considerations on the influence of racist practice and thought on the social and cultural relations and on the invisibilization of black slavery in the English official history. Andrea Levy's fiction is seen as the means used by the writer to take a stand before historic omissions, and two short stories which highlight the relationship between black colonials and the white hegemony are analyzed to exemplify such fictional praxis, "That polite way that English people have" and "The empty pram".
\end{abstract}

Keywords: Andrea Levy: Identity; Englishness; Black immigration; Belonging

\section{Andrea Levy e a afirmação da identidade negra britânica: entre a amnésia e a reivin- dicação da história negra no Caribe}

A questão identitária tem se tornado, contemporaneamente, um dos mais pertinentes e fre- quentes motivos de interrogação e estudo. Este ensaio examina a forma como a ficcionista inglesa negra Andrea Levy tem interrogado a identidade britânica a partir do lugar ocupado por ela como cidadã britânica, descendente de imigrantes caribenhos negros. Assim colocado, esse questionamento

\footnotetext{
* Doutora em Letras (Literaturas de Língua Inglesa, UFRGS), com estágio pós-doutoral em na UFF (Estudos de Literatura). É docente no Departamento de Linguística, Letras e Artes da Universidade Regional Integrada do Alto Uruguai e das Missões (URI), câmpus Frederico Westphalen. Integra o GT Relações Literárias Interamericanas da ANPOLL, e os Grupos de Pesquisa Literatura, História e Imaginário e Comparatismo e Processos Culturais (URI- CNPq). Pesquisa e publica especialmente sobre identidade, memória, história, violência, literatura brasileira e literaturas pós-coloniais de língua inglesa. E-mail: dnsalmeidasilva@ gmail.com
} 
situa-se no quadro da interrogação da inglesidade (Englishness) que vem à tona a partir do momento em que os habitantes da metrópole veem-se frente à frente a seus coloniais, e especialmente a seus coloniais negros.

Esta é uma situação que, nitidamente, envolve um confronto baseado na construção de identidades culturais contrastantes. Como os estudiosos dos estudos culturais têm repetidamente afirmado, a identidade é construída relacionalmente, a partir da comparação entre os indivíduos e seus outros, pelo que envolve, inevitavelmente, o estabelecimento da diferença. Esta, contudo, não necessita ser construída a partir de hierarquização preconceituosa, embora na maioria das vezes o seja, já que aquele que se compara a seus outros usualmente toma a si próprio como parâmetro superior, em relação ao qual os outros são avaliados.

Por séculos, a Grã-Bretanha fora impulsionada, em grande parte, pelo empreendimento colonial. Contudo, pouco sabiam os cidadãos britânicos da história de despossessão e violência que transcorria em suas colônias - refiro-me, mais especificamente, ao contexto das colônias do Caribe, já que é a esta região que o imaginário da autora aqui em estudo está ligado. Nessa região, a economia erigida em torno do sistema de plantation dependia do cultivo da cana e do tabaco. Conforme James Walvin (2001) registra, entre o século XVIII e o século XIX o consumo de açúcar pelos britânicos cresceu de 4 para 18 libras - tornaram-se, então, dependentes do açúcar, o qual era generosamente usado em pratos altamente elaborados pelas classes médias e alta. Por volta da metade do século dezoito, haviam-se tornado tão viciados em tabaco quanto em açúcar: enchiam seus charutos com eles, mastigavam-no, moíam-no até se tornar em fino pó e aspiravam-no. $\mathrm{O}$ tabaco manchava suas roupas, mãos e cabelos, e poluía a atmosfera de suas reuniões.

O tabaco e, mais particularmente, o açúcar eram cultivos para os quais a mão-de-obra escrava tornou-se indispensável, pelo seu baixo custo - econômico, mas não humano. Este último foi cuidadosamente oculto tanto do cidadão inglês médio como do próprio colonial. Conforme Andrea Levy testemunha em seu ensaio "Back to my own country" (2014), durante toda a sua experiência nos bancos escolares na Inglaterra tudo o que aprendeu sobre a presença britânica no Caribe resumiu-se a uma aula sobre o comércio negreiro transatlântico, na qual se mostraram, a ela e aos colegas, fotos de escravos em navios. Mais espaço era concedido, no currículo escolar, ao estudo da escravidão na América do Norte do que àquela praticada por seu próprio país. Contudo, como Levy avalia em retrospecto, não apenas a escravidão nos Estados Unidos diferiu da praticada no Caribe, onde o número de escravos em muito ultrapassava o de seus senhores brancos, como cada nação precisa compreender seu próprio passado e legado histórico: "America's story will not do for us. Our legacy of slavery is unique, and we need to understand what it is." (LEVY, 2004, p. 15).

O virtual apagamento da escravidão britânica no Caribe é, para a autora, mais que uma ausência ou descontinuidade na história nacional, uma deliberada amnésia. É, pois, indissociável do campo da memória cultural. O conceito deve, aqui, ser relativizado: como Aleida Assmann (2011, p. 216) ressalva, instituições e grupos sociais maiores, como nações, estados, comunidades não "têm" uma memória, mas a "constroem" para si mesmos, separando o que parece útil ou relevante ou não. Percebe-se, assim, que esse é um registro que procede por meio de exclusões e hierarquização, contexto em que é frequente a cumplicidade com o poder, pois, como Paul Connerton (2012) salienta, a transmissão, preservação e controle memorial condicionam, em grande parte, a hierarquia de poder de uma dada sociedade. Percebe-se, assim, que sua preservação é mais do que apenas uma operação de natureza técnica: o passado, ou aquilo que dele foi preservado de acordo com a política memorial de cada comunidade importa, porque imagens do passado legitimam a ordem social presente. Por outro lado, fica evidente que indivíduos ou grupos à margem da sociedade podem ter sua memória distorcida ou invisibilizada.

$\mathrm{O}$ apagamento memorial no contexto britânico aqui referido tem reduzido o negro ao status de 
alienígena em sua própria pátria. No entanto, integrantes dessa população negra que agora habitam a metrópole são, em grande parte, descendentes dos negros que aportaram à Inglaterra como cidadãos britânicos, e estes eram os descendentes dos escravos trazidos pelos britânicos da África para a colônia. Como Levy descreve com ironia, "all this happened three thousand miles away from Britain, and as a result it has been possible for it to quietly disappear from British mainstream history" (LEVY, 2014, p. 14).

A propósito dessa amnésia histórica, a autora narra o caso de dois cidadãos britânicos a quem descreve como brilhantes e dotados de educação universitária, os quais, em ocasiões distintas, durante as entrevistas de lançamento de The long song, romance que se passa no contexto da sociedade escravocrata do Caribe, confessaram a Levy que desconheciam totalmente o fato de que a escravidão tinha sido adotada pela Inglaterra no Caribe - a escravidão, pensavam, tinha ocorrido só na América do Norte.

Outro acontecimento que impactou a Levy, relatado, ainda, no já citado ensaio, foi o testemunho do tratamento dispensado a um negro no ônibus. Transcorria o início da década de 1960, e Levy era, então, uma adolescente. Naquele tempo, a presença negra entre os brancos era rara, e a visão de um único homem negro no ônibus que, sorridente e educadamente, tentava entabular conversa com os outros passageiros, sendo totalmente ignorado, impactou profundamente a Levy. Sabia que, como seus pais, havia imigrado do Caribe. Sabia que, como seus pais, era um homem bom, e que os passageiros gostariam dele se pudessem conhecê-lo. Se, para estes últimos, o solitário negro era, mais que um estranho, um completo alienígena, para a Levy adolescente, ele era inescapavelmente familiar. Compreendia os equívocos que ali se travavam, de parte a parte. E tudo porque ele era diferente: tinha aparência diferente e soava diferente -- ele que deveria ter-lhes sido tão familiar, pois era parte de seu antigo império.

Ambivalentemente, Andrea Levy sente pena daquele homem, mas fica, também, incomodada com sua presença. Em sua casa, seus pais pensavam que, para progredir na Inglaterra, deveriam "saber seu lugar", e quietamente, sem espalhafato, viver respeitavelmente, manter a casa e o corpo em ordem e limpos, e cuidar do espírito na igreja, aos domingos. Julgavam que deveriam, em suma, assimilar tanto quanto possível a cultura local; assim, o pai era corrigido quando falava com sotaque jamaicano, ou incluía em seu linguajar expressões que pudessem trair sua origem, como "nah man" e "cha". Como a autora resume, era crença de seus pais que, se não fizessem nada fora do comum que pudesse incomodar aos ingleses, poderiam permanecer no país deles. O possessivo que aponta para a posse alheia justifica-se porque os cidadãos coloniais britânicos negros julgavam-se sem direito algum no país ("no real entitlement to anything"), pois eram imigrantes e deviam aceitar o que quer que lhe oferecessem - "they [believed] they must accept what this country was willing to give" (LEVY, 2014, p. 7). Cito a autora, pois são palavras fortes que acentuam o sentimento de não pertencimento daquela geração de imigrantes.

Parte da cultura assimilativa incluía a eliminação total de histórias e memórias da Jamaica nas conversas familiares, a tal ponto que foi só depois de adulta que Andrea Levy veio a tomar conhecimento da história familiar, quando, ao compreender a importância de recuperar sua história pessoal e a do lugar que seus pais haviam chamado de pátria, descobre na escrita uma forma de autoconhecimento, um meio instrumental para interrogar e compreender a si mesma e a sua historia familiar e nacional. Nesse momento, passa a interrogar sua mãe acerca da família e da vida na Jamaica.

$\mathrm{O}$ questionamento da identidade britânica negra levada a cabo por Levy desenvolve-se, pois, a par de sua preocupação com seu pertencimento, questionamentos que são motivados pelo virtual apagamento, da história britânica, de sua interferência nas ilhas do Caribe. Embora Levy reconheça que, mesmo apenas no contexto da história colonial britânica, a narrativa das possessões no Caribe não figure entre as mais proeminentes, ainda assim esta integra sua história tanto quanto o fazem a conquista norman- 
da, ou os Tudors. É uma história que, a sua maneira, apresenta particularidades relevantes tanto para os ingleses da metrópole como para os coloniais, distinguindo-se por dizer respeito não só a uma das primeiras possessões coloniais, como a uma das mais longas, e que mais se distingue em termos de formação de uma população mista. Essa é uma história que permanece, pois se em outras sociedades colonizadas pode-se falar do declínio da herança britânica em termos institucionais e administrativos, no Caribe tudo resulta da interferência dos britânicos nas ilhas, das cidades à população mista e sua cultura híbrida. Por outro lado, Levy ressalta que da vivência britânica no Caribe resultou importante legado cultural e econômico que embasou não só o crescimento da Inglaterra como poder mundial e a construção de sua autoimagem como suas atitudes com respeito à raça. (LEVY, 2014, p. 16)

As observações de Levy parecem enfatizar a inevitável transitividade e complementaridade existente no relacionamento entre metrópole e colônia, um fato que tem, já, sido repetidamente exposto por estudiosos da pós-colonialidade e dos estudos culturais como Homi Bhabha e Stuart Hall. Também Simon Gikandi (1996), ao enfocar mais especificamente os efeitos do "encontro colonial" sobre a escrita, identidade e cultura inglesa, aponta a necessidade de compreender e construir esquemas identitários que contrariem a tradição de estabelecer uma diferença radical entre a metrópole e suas colônias, já que a própria concepção de inglesidade foi um produto da cultura que aquela pensava ter estabelecido em outros lugares. $\mathrm{O}$ autor atesta, também, como, em sua própria história, fica visível o apagamento da história colonial da cultura britânica: quando estudante foi incapaz de compreender a extensão pela qual o colonialismo chegara a moldar o caráter do espaço doméstico. Reconhece, agora, que este dominou cada faceta de sua vida e experiência, sem que fosse associado à cultura da Grã-Bretanha ou a seu cânone literário, no qual é prática comum separar a grande tradição da literatura inglesa do novo corpo de escrita produzido nas antigas colônias. Gikandi sublinha:
[...] at the twilight of the modern age [...], an examination of the function of colonialism in the shaping of modernity is not an act of theoretical reversion; on the contrary, it is an attempt to name - and thus to come to terms with - the hitherto invisible specter whose presence we have felt around us, whose effectivity we have encountered in the texts of our identity, but whose logic we could not name until now. (GIKANDI, 1996, p. 3)

É justamente a consciência da não dissociação da história doméstica da Inglaterra da de suas colônias além mar ("Britain made the Caribbean that my parents came from. [...] In return my ancestors, through their forced labour and their enterprise, contributed greatly to the development of modern Britain") (LEVY, 2014, p. 18) e o reconhecimento da ignorância, tanto por parte da população branca, como por parte de britânicos de ascendência afrocaribenha, da relevância da contribuição negra para o país que estimulam Levy a narrar essa história oculta. Em suas palavras: "My heritage is Britain's story too. It is time to put the Caribbean back where it belongs - in the main narrative of British history" (LEVY, 2014, p. 18). Como Woodward (2000) lembra, indivíduos ou grupos que reivindicam uma identidade não se limitam a ser posicionados por ela, mas eles mesmos posicionam-se a si próprios, com o objetivo de transformar as identidades históricas, herdadas de um suposto passado comum. Nesse processo, é fundamental o reconhecimento do lugar de onde um indivíduo fala, sua temporalidade e localidade próprias, pois, segundo Asante (2009), é somente quando um indivíduo se vê como ocupando o centro em sua própria história que passa a visualizar a si próprio como agente.

O exame da história negra nacional e da exploração e pesquisa acerca de seus próprios vínculos familiares corresponde à conscientização, por Andrea Levy, da importância da memória de origens e, por outro lado, a sua descoberta de que a obliteração da história do Caribe negro representa uma política memorial instituída. Conforme depõe, na ânsia de construir vínculos na Inglaterra, seus pais optaram por silenciar totalmente acerca da Jamaica e da fa- 
mília que ainda lá vivia; ademais, as conexões entre a pátria de seus pais e as possessões inglesas no $\mathrm{Ca}$ ribe eram um assunto pelo qual não se interessava em sua juventude. Embora tivesse já a percepção da posição peculiar ocupada pelos negros na Inglaterra, desconhecia a importância da memória de origem e pensava que poderia construir seu futuro desvinculada do conhecimento do passado. Na entrevista concedida a Susan Alice Fischer (2005) diz:

Before I wasn't so interested in the link between Jamaica, the Caribbean and Britain. I was much more, 'We are black British, we're here, and how are we going to move on?' And that's absolutely part of what I do, too, but I didn't think that looking backwards was so important, whereas now I think it is absolutely important and so fascinating. (2005, p. 123)

A escrita foi a forma escolhida por Levy para posicionar-se frente a essa omissão histórica e, assim, provocar uma reavaliação que leve ao reconhecimento da contribuição negra e, pois, à transformação da identidade negra até agora historicamente constituída. Na próxima seção, analisam-se dois dos seis contos que integram o volume Six stories and an essay (2014): "That polite way that English people have" e "The empty pram", os quais retomam temas e situações recorrentes na obra de Andrea Levy: identidade, pertencimento, raça, classe social, imigração e lugar do imigrante na sociedade inglesa, enfocados a partir, sobretudo, da experiência pós-Windrush, a partir da segunda metade do século XX.

Esse momento é fundamental para o estudo da identidade britânica pois, dado o caráter relacional da identidade cultural, era preciso um contato com seus outros para que os ingleses, e também aqueles, pudessem se redefinir quanto a sua inglesidade e, pois, quanto ao lugar ocupado na Inglaterra. Além disso, para Andrea Levy, esses não são fatos meramente históricos, mas vividos e sentidos no ambiente familiar próximo. Conforme a autora relata (2014), seu pai foi um dos passageiros que aportou em Tilbury em 1948, a bordo do Empire Windrush. Já a mãe deslocou-se para a Inglaterra a bordo de um cargueiro da Jamaica Banana Produ- cers. Na Jamaica, ambos desfrutavam uma vida de classe média: suas famílias possuíam casas amplas, servidas por empregados. O pai exercia a função de contador junto a várias firmas, inclusive Tate \& Lyle (companhia britânica que tem liderado a indústria de produção de açúcar por mais de 130 anos), e a mãe era professora. $\mathrm{O}$ contraste entre as condições sociais e profissionais ocupadas na Jamaica e as do novo país é marcante: o pai empregou-se nos correios, a mãe foi, durante muito tempo, proibida de exercer a profissão de professora. Moraram em pequenos quartos até que fossem abrigados em uma council state house, vizinhança em que passaram a conviver com outros britânicos pobres; eram, porém, os únicos negros. Levy resume: "In England, the fabled Mother Country that they had learned so much about at school in Jamaica, my parents were poor and working class" (2014, p. 6).

A vivência familiar é recorrentemente tematizada por Levy. Sua obra de estréia, o buildungsroman Every light in the house burnin' (1994), é frequentemente descrito como autobiográfico, e relata a transição para a vida adulta de uma jovem moradora no norte de Londres cujos pais eram imigrantes vindos da Jamaica, a qual se questiona acerca de sua verdadeira identidade. O segundo romance, Never far from nowhere (1996) igualmente examina a questão do pertencimento, e suas protagonistas Vivien e Olive desenvolvem perspectivas contrastantes sobre que lugar chamar de lar, a Inglaterra ou a Jamaica. Segue-se um terceiro romance, Fruit of the lemon (1999), em que a protagonista, Faith Jackson, volta à Jamaica natal de sua família, onde descobre suas raízes culturais e familiares. Ambientado na Inglaterra, à época da Segunda Guerra Mundial, Small island (2004) tem como protagonistas um casal de imigrantes caribenhos negros, Hortense e Gilbert Joseph, e seus hospedeiros britânicos Queenie e Bernard, um relacionamento que simboliza outros encontros interraciais e intersociais ocorridos na ilha maior, a Inglaterra. O último romance publicado até o momento, The long song (2010) transcorre na sociedade escravocrata da Jamaica, e tem como protagonista uma jovem escrava, July, a qual vive 
na plantation Amity os anos finais do escravismo e a posterior transição para a liberdade.

\section{O colonial e a metrópole: visões e revisões}

"That polite way that English people have" foi escrito por Andrea Levy em resposta a uma solicitação para que escrevesse algo que se centrasse na ideia de calor de ou frio. Como, à época, estivesse escrevendo Small island, romance que envolve o deslocamento de indivíduos da Jamaica para a Inglaterra, Levy optou por explorar a imigração de um país quente para um país frio. A opção é significativa, pois a menção a calor ou frio em romances de migração ${ }^{1}$ tem, mais do que alusão climática, se constituído em metáfora sobre a natureza das pessoas em cada sociedade. Assim acontece, por exemplo, no romance Voyage in the dark (1934), da também autora caribenha Jean Rhys, no qual a protagonista, Anna Morgan, contrasta o clima quente e os relacionamentos igualmente calorosos que conhecera em sua Dominica natal com a ambiência gélida da Inglaterra.

A narrativa em "That polite way that English people have" tem lugar no contexto da imigração negra britânica da fase medial do século XX e, segundo a autora (2014), foi inspirada por histórias narradas por sua mãe acerca de sua viagem da Jamaica para a Inglaterra em 1948. O conto passa-se, em grande parte, no interior do navio que transporta a protagonista, Blossom, para a Inglaterra, a sonhada pátria-mãe. Em seu deslocamento entre o Caribe e a Inglaterra, ao proporcionar interação e relativa proximidade entre ingleses da metrópole e seus outros da colônia, o navio vem a se constituir, no contexto do conto, em microcosmo no qual as preconcepções de Blossom sobre a Inglaterra e os ingleses e seu senso de identidade e pertencimento são postos à prova.

O conto inicia com reflexões da protagonista acerca de um casaco comprado de sua patroa, que retornara há pouco da Inglaterra, para onde fora com a finalidade de levar dois filhos para um internato em Dover. Torna-se claro que Blossom, que já de há muito se preparava para emigrar, desejava, em
Londres, ser considerada uma mulher de alta classe vinda da Jamaica, e vê no casaco um meio de demonstrar esse status, já que julga que este, por sua qualidade superior, atrairia admiração positiva de todos sobre si. Dessa forma, os parágrafos iniciais já deixam clara sua propensão afiliativa para com a Inglaterra e os ingleses (estes últimos inicialmente representados pela patroa e a confiança que nela demonstrava), sua concepção do país como o representante máximo do refinamento, e o desejo de ser tão distinta quanto aqueles a quem tanto admira.

Dado o valor simbólico do casaco no contexto do conto, sua aparência, valor e compra são descritos em detalhe. É preto, longo; em seu afã de impressionar os londrinos, Blossom planeja com que chapéu o usará, e em que ângulo o posicionará em seu rosto. Mais detalhes, contudo, são dados sobre o local e valor da compra: é um dia extremamente quente, e a patroa dá-lhe permissão para entrar em seu quarto e provar o casaco, assegurando-lhe que parecia ter sido feito para ela; pede um alto valor por ele, pois, diz, seu preço havia subido muito desde a guerra. A descrição deixam, pois, claras, a relação de inferioridade entre Blossom e a patroa, e a inutilidade, para esta última, da vestimenta em um ambiente extremamente quente. Enquanto a alusão à guerra sugere o tempo em que se passa a história e a associa aos deslocamentos de negros que se seguiram à viagem inaugural do S. S. Empire Windrush, os argumentos usados para convencer Blossom, típicos de vendedor, iniciam a lançar dúvida sobre a honestidade da patroa e sobre a capacidade da protagonista de reconhecer em quem deve confiar.

$\mathrm{Na}$ sequência, Blossom não apenas confessa não dar ouvidos às advertências da mãe com respeito aos seus planos para emigrar, deixando seu país e se estabelecendo na Inglaterra, como rebate um a um seus argumentos, expressando a certeza de que isso era o melhor que poderia fazer para assegurar a si um bom futuro, e a sua mãe. Ademais, afirma, as condições climáticas da Jamaica eram, sim, motivo que justificava seus planos, dado o calor extremado e os furacões destruidores; não era demais o dinheiro empregado na compra da passagem, pois para 
isso economizara. Quanto à objeção de que poderia estudar para enfermeira em seu próprio país, a Inglaterra lhe daria mais: além de bela casa, com canteiros de rosa, tomaria chá com e como os ingleses, nos mais requintados lugares. Imagina que a mãe, criada no campo, não podia entender seus motivos: não era o que os ingleses chamariam de refinada, como a patroa em cuja residência servira por dez anos, e que pertencia a uma das mais tradicionais famílias britânicas da ilha.

Tal como desdenha as objeções e conselhos da mãe, Blossom sente-se incomodada com a rusticidade do jamaicano que carrega as malas para a cabine dupla que ela reservara somente para ela. Soa-lhe como pura inveja a advertência dele ao sair da cabine: "Remember you're a nigger" (LEVY, 2014, p. 63). Contrastam com esse homem a maioria dos passageiros do navio, ingleses retornando de férias ou em viagem de negócios ou de visita a familiares. Ainda imbuída de irrestrita admiração à metrópole, admira a maneira polida com que os ingleses se cumprimentam, e deseja encontrar um passageiro dos mais refinados dentre eles, cuja companhia lhe assegure seu próprio valor: "[...] a first-class passenger among English people. Someone to say there is Blossom Hunter, a highclass woman waiting to voyage on a adventure do the Mother Country" (LEVY, 2014, p. 64).

Pouco depois, um homem a quem descreve como o mais lindo cavalheiro que já tinha visto posta-se a seu lado, um "proper English gentleman" (LEVY, 2014, p. 66). Blossom imagina-o como alguém de prestígio social: médico, advogado ou gerente de banco. $\mathrm{O}$ homem dirige-se a ela com polidez, aperta-lhe a mão, diz esperar revê-la à noite. No jantar de gala, para o qual, como todos os outros, Blossom veste seu melhor vestido (embora a descrição do traje de mangas bufantes feito para uma festa anos atrás sugira que já esteja fora de moda), e sente-se infinitamente valorizada quando Philip Keyes pede sua companhia. Blossom sente que, ante tal cavalheiro, seu nome é inadequado e, deixando de lado o nome pelo qual era conhecida entre os seus, passa a adotar seu nome de batismo, Hortense Hunter, fato que é altamente sugestivo.
Nomear é singularizar alguém, distinguido-o dos outros através de seu apelativo; em alguns contextos, o nome indica os desejos dos pais para o caráter e futuro de seus filhos. Ao trocar de nome, a protagonista expressa seu desejo de descontinuar sua história até então, iniciando uma nova vida junto aos ingleses.

Logo, contudo, revela a extensão de sua ignorância acerca do país para onde se dirige e sua incapacidade para se comunicar com os ingleses. Escapa-lhe o riso divertido de Keyes quando afirma que tem profundo conhecimento da Inglaterra, adquirido através da leitura de livros e, para comprovar seus conhecimentos, cita lugares famosos como Hyde Park e Regent's Park; declarando-se ansiosa por ver os narcisos ("daffodils"), incorpora à sua descrição dos mesmos expressões retiradas do conhecido poema de Wordsworth, "I wandered lonely as a cloud". Mais tarde, demonstra seu desconhecimento da língua que chamava de sua quando não compreende o convite de Keyes para um "night cap", pelo que ele a descarta como companhia, escolhendo antes Petal, mulher cuja presença Blossom desdenhara.

Petal é construída como a encarnação de tudo aquilo que a nova Blossom - Hortense - despreza e gostaria de deixar para trás: rude, sem refinamento, deselegante, inconveniente. Sem ser convidada, assenta-se à mesa que Blossom partilhava com Keyes, introduzindo-se na conversa. A primeira expressão usada para descrever a mulher, porém, resume o que parece ser a razão primeira para sua inadequação: "Then this woman - a Jamaican as black as night - sat down at our table" (LEVY, 2014, p. 69). Mais do que a intromissão, o que definitivamente motiva o desprezo expresso em "this woman" é o fato de que é negra.

Por séculos, um rígido código racial havia dominado as relações entre ingleses e jamaicanos, de acordo com o qual as nuances de cor mais claras, mais próximas do ideal de branquitude, asseguravam um lugar privilegiado junto à hegemonia branca; negros com pigmentação de pele mais clara consideravam-se superiores aos mais escuros. Lembrando 
o processo de desenraizamento cultural provocado por essa formação cultural caribenha, Stuart Hall relata, em entrevista concedida a Jonathan Derbshire, como construía, em sua infância, superioridade baseada em classe social e código de cor: " $M y$ family belonged to a very particular formation - middle-class and coloured, not black. That meant it had a closer connection to the plantocracy that many other people didn't. So I didn't feel like an ordinary black Jamaican boy." O estudioso narra, ainda, como os pais proibiam trazer crianças negras para dentro de casa, bem como relacionamento íntimos com negros.Também Andrea Levy testemunha que o sistema de classe herdado da Inglaterra influenciou na escolha de companheiros de folguedo quando criança: nascida em uma família que ela define como " $i$ ght skinned", era proibida pelo pai de brincar com crianças mais escuras do que ela; na Inglaterra, com felicidade, os pais criaram-na entre crianças brancas - então classe social operava como equalizador em termos de moradia. Contudo, para os pais dessas mesmas crianças brancas, os Levy não passassem de imigrantes negros, não pertencentes, o que era sinalizado por perguntas como: "'When are you going back to your country?' ' Why are you here?' 'Why is your food so funny?' ' Why does your hair stick up?' 'Why do you smell?" (LEVY, 2014, p. 8). Essas formas de racismo, embora fisicamente não violentas ou extremas, eram psicologicamente devastadoras, e Levy veio não só a odiar a si mesma como a envergonhar-se de sua família e do fato de que viera do Caribe. Uma vez que a questão da branquitude está tão profundamente entranhada nas relações sociais aceitas em sua cultura familiar e nacional, não estranha que as tematize em suas criações.

Amparada na certeza de sua superioridade racial e social, Hortense despreza o convite à amizade e companheirismo expresso no vocativo "sister", com que Petal se dirige a ela. Ignora-lhe as tentativas de entabular conversa e assegura aos demais convivas que a mulher não é seu parente. Contudo, Petal mostra-se muito mais capaz de compreender códigos sociais, e situar os outros e a si mesma dentro de expectativas e posições mais realistas. Reco- nhece em Blossom apenas uma "country girl", e ri-se quando ela afirma ter conhecido o refinamento no seio de uma das mais destacadas famílias inglesas. Entende as reais intenções da sociabilidade de Keyes, e tira partido delas. Não ignora as dificuldades que uma imigrante negra terá para encontrar colocação e moradia em Londres, e oferece a Hortense seu endereço, e a possibilidade de compartilhar um quarto com ela. A protagonista, contudo, despreza-a como inadequada e não merecedora da amizade, certa de que logo estaria circulando entre ingleses.

Ao final do conto, terra à vista, Hortense sente-se preparada para sua nova vida. Comparando-se a Petal, julga que não é como aquelas que vêm à Inglaterra sem preparo, e elege como símbolo de sua certeza o abrigo adquirido de sua patroa inglesa, o qual considera o melhor e mais fino casaco da Inglaterra. $\mathrm{O}$ conto encerra-se com o golpe final desferido por Petal, que de novo ri da ignorância de Hortense e revela-lhe que a patroa havia-lhe vendido algo feio e fora de moda, praticando, assim, um verdadeiro roubo. O final, aberto, não revela o quanto ou quão bem Hortense é capaz de assimilar que os ingleses, com as maneiras que lhe parecem sempre tão polidas, não são o que parecem ser - um fato que antecipa o conhecimento, por parte do leitor, de que seu futuro em Londres não será, também, o que antecipa ser.

O segundo conto escolhido para análise, "The empty pram", centra-se nos momentos iniciais do contato do colonial da geração Windrush com os cidadãos ingleses em Londres. Inicia com a rememoração de uma mulher que, ao recordar como esforçava-se para limpar o chão do pequeno quarto que seu marido conseguira alugar, confessa não ter estado preparada para o encontro com seus outros, e toda a sua estranheza. Esta é dimensionada através da narração do primeiro desses encontros: três dias após chegada a Londres, um menino bate a sua porta, carregando um nenê de tal forma que quase o sufoca. O menino é descrito como branco, louro; a narração insinua pobreza, baixa classe social e pouca assistência familiar - o menino é extremamente magro e porta óculos tão sujos que os olhos ficam visíveis em 
apenas uma das lentes. A imigrante, não nominada - representa outras tantas, incompreendidas e invisíveis aos olhos de seus outros - toma o nenê dos braços do menino, salvando-o de uma possível queda ou sufocamento; o menino foge, e ela sai à procura da mãe do bebê.

Consciente de que está carregando um nenê que fora roubado, vê um carrinho de bebê, e espera que esteja desocupado, o que significaria que sua procura estava finda. Escuta um grito, e localiza um grupo de mulheres em grande comoção, e um carrinho vazio, pelo que se dirige a elas, e indaga se aquele era o bebê. Imediatamente o bebê é arrancado de suas mãos, e as três mulheres escudam-no, com o corpo, protegendo-o da presença da desconhecida, que explica toda a situação. Uma das mulheres diz não compreender o que ela diz; logo a protagonista é identificada como raptora, e a polícia chamada.

A situação é interrompida pela chegada do menino raptor, que acusa a mulher (a quem chama de "woolen-haired", singularizando-a, preconceituosamente, a partir de seu fenótipo) de ter roubado o bebê dele. Uma das mulheres que acusam a imigrante revela-se como a mãe do menino, e seu pedido para que deixe os bebês em paz revela que roubar nenês é um hábito de seu filho. Nesse momento, o tratamento das mulheres para com a estrangeira muda: a mãe do bebê agradece a devolução do filho, as mulheres oferecem-lhe chá e, em sinal de amizade, tocam-lhe nas costas e no ombro, um gesto que a desconhecida iguala ao tratamento dado a cachorros. Nenhum castigo é dado ao menino, que é acariciado, mas as mulheres condenam a imigrante por não lhes ter esclarecido a situação antes. Estranhamente, agora entendem seu inglês, uma prova de que não era propriamente a língua que a invisibilizava a seus olhos.

Ambos os contos retomam cenas da história inglesa que presentificam fatos e relacionamentos que têm sido escamoteados do conhecimento do grande público devido à "amnésia" denunciada por Levy. Se a autora tão energicamente reivindica essas narrativas soterradas é porque compreende, por vivência própria, como a descontinuidade memorial promo- vida pelo Estado afeta o censo identitário: rouba aos cidadãos negros o conhecimento que os faria se orgulhar de seu trabalho, resiliência e contribuição à nação, e que levaria a reforçar e justificar seu senso de pertencimento. Por outro lado, inviabiliza o conhecimento que poderia levar a população branca a compreender como e por que seus conterrâneos negros aportaram à Inglaterra, e, portanto, seu direito de lá viver. Escritas sem rancor, e até com considerável humor, as narrativas de Levy têm chamado a atenção de britânicos de todas as etnias, contribuindo para trazer à luz arquivos memoriais e históricos que só recentemente têm sido revisitados.

\section{Nota}

1. Considera-se migração em seu sentido lato, como todo o movimento populacional. No contexto deste estudo, migração refere-se tanto ao ato de emigrar (saída espontânea de um país para morar em outro, temporária ou definitivamente), como de imigrar (deslocamento para e/ou entrada em um país estrangeiro, com intenção de se estabelecer no mesmo). Os derivados desses verbos - migrante, emigrante e imigrante - são empregados de acordo com sentido idêntico.

\section{Referências}

ASANTE, Molefi Kete. Afrocentricity. In: Molefi Kete Asante (blog), 13/04/2009. Disponível em:http:www. assante.net/articles/1/afocentrity. Acesso em: 07/05/2016

ASSMANN, Aleida. Memory, individual and collective. In: GOODIN, Robert E.; TILLY, Charles. The Oxford handbook of contextual political analysis. Oxford: Oxford University Press, 2011. p. 210-224.

CONNERTON. Paul. How societies remember. Cambridge: Cambridge University Press, [1989] 2012.

FISCHER. Andrea Levy in conversation with Susan Alice Fischer (2005 and 2012). In: BAXTER, Jeannette; JAMES, David. (ed.). Andrea Levy: contemporary critical perspectives. London: Bloomsbury, p. 121138.

GIKANDI, Simon. Maps of Englishness: writing identity in the culture of colonialism. New York: Columbia University Press, 1996.

HALL, Stuart. We need to talk about Englishness. New Statesman. 23 ag 2012. (entrevista concedida 
a Jonathan Derbyshire). Disponível em: www. Newstaesman.com/politics/uk_politics/23aug2012. Acesso em: 22 maio 2016.

LEVY, Andrea. Six stories and an essay. London: Tinder Press, 2014.

Back to my own country. In: Six stories and an essay. London: Tinder Press, 2014. p. 3-18. That polite way that English people have. In:_. Six stories and an essay. London: Tinder Press, 2014. p. 59-75.

.The empty pram. In: Six stories and an essay. London: Tinder Press, 2014. p. 97-101.

WALVIN, James. Black ivory: slavery in the British empire. $2^{\text {nd }}$ ed. Oxford: Blackwell, 2001.

WOODWARD, Kathryn. Identidade e diferença: uma introdução teórica e conceitual. In: SILVA, Tomaz Tadeu (org.); HALL, Stuart; WOODWARD, Kathryn. Identidade e diferença: a perspectiva dos Estudos Culturais. Petrópolis: Vozes; 2000. p. 7-72.

Recebido em: 10/08/2016 Aceito em: 24/10/2016 